communicate more effectively with policymakers about the evidence base that supports injury prevention policy interventions. Description of the Problem Despite a growing evidence-base of effective injury prevention policies, translating and disseminating effective interventions to policymakers remains a challenge. As a result, the reach and impact of the injury prevention field is limited.

Results The consortium model for evidence-based policy is a response to this need. The consortium process involves bringing together experts representing stakeholder interests (including researchers, advocates, and practitioners) from different disciplinary backgrounds to review the evidence about a topic, identifying areas of consensus that support policy recommendations, and disseminating the findings and recommendations to policymakers through multiple channels. To date we have engaged in three consortium initiatives on: 1) mental health and gun violence; 2) smoke alarms and residential fires; and 3) prescription drug overdose. The three initiatives are at different stages in the consortium process. Effective dissemination of the findings and recommendations from the mental health and gun violence initiative has resulted in policy change at the national and state levels in the United States. Reports from the smoke alarm and prescription drug efforts have been released and plans for dissemination to policymakers are underway.

Conclusions The consortium model for engaging researchers, advocates, and practitioners in translating the evidence on a particular topic into policy recommendations and disseminating those recommendations to policymakers is a promising approach. Lessons learned from across the three initiatives include how to effectively: 1) identify and engage participants in the consortium process; 2) produce findings and recommendations that will engage a policy response; and 3) respond to policymaker interest in the consortium's work. Opportunities to adapt and replicate this model in countries other that the United States should be pursued.

\section{ADDRESSING AUSTRALIAN ABORIGINAL CHILD INJURY THROUGH POLICY AND PRACTICE GUIDELINES}

${ }^{1}$ Kathleen Clapham, ${ }^{2}$ Rebecca Ivers, ${ }^{2,3}$ Kate Hunter, ${ }^{1}$ Keziah Bennett-Brook. ${ }^{1}$ Australian Health Service Research Institute, University of Wollongong, Australia; ${ }^{2}$ The George Institute for Global Health, the University of Sydney, Australia; ${ }^{3}$ The Poche Centre for Indigenous Health, the University of Sydney, Australia

\subsection{6/injuryprev-2016-042156.203}

Background Despite increasing knowledge about the burden of unintentional injury among Australian Aboriginal children there is a lack of effective programs targeting Aboriginal children and families. Moreover, little is known about how Aboriginal people engage in child injury prevention programs. Research was conducted to inform the development of guidelines for effective injury prevention approaches targeting injury among Aboriginal children. We also worked closely with investigators on an Australian version of guidelines modelled from the European Child Safety Alliance.

Methods In a staged process we conducted: (a) a review of effective injury prevention programs targeting Australian Aboriginal children; (b) qualitative research with practitioners and Aboriginal community members to explore attitudes to the prevention of injury and behaviours and perceptions of risk; (c) round table discussions with Aboriginal community members, injury practitioners and policy makers.
Results A series of case studies of effective programs was developed. The project adopted a "best buys" approach to identifying programs with the most promise to address the burden of Aboriginal child injury; this was matched with community views and preferences about acceptable and appropriate programs and strategies. Guidelines also incorporated principles for successful engagement with Aboriginal communities including how to work with Aboriginal children and families when developing programs for unintentional injury prevention and the most appropriate methods for their evaluation.

Conclusions The guidelines are expected to inform the development of policies and programs targeting child injury in the Aboriginal population in New South Wales. They will contribute to ensuring that the efforts and resources of policy makers and practitioners are based on the views and experiences of Aboriginal communities and raise awareness within the Aboriginal community by informing the further development of social marketing campaign around injury prevention.

\section{THE CANADIAN INJURY PREVENTION CURRICULUM: USING AN INTEGRATED KNOWLEDGE-TRANSLATION APPROACH}

${ }^{1,2,3}$ Sarah A Richmond, ${ }^{4}$ Kathy Belton, ${ }^{5}$ Jennifer Heatley, ${ }^{3}$ Amanda Black, ${ }^{2}$ Liraz Fridman, ${ }^{6}$ Allison Ezzat, ${ }^{2}$ Tessa Clemens, ${ }^{6}$ lan Pike, ${ }^{2}$ Alison Macpherson. ${ }^{1}$ Hospital for Sick Children, Canada; ${ }^{2}$ York University, Canada; ${ }^{3}$ University of Calgary, Canada; ${ }^{4}$ Injury Prevention Centre, Canada; ${ }^{5}$ Nova Scotia Department of Health and Wellness, Canada; ${ }^{6}$ University of British Columbia, Canada

\subsection{6/injuryprev-2016-042156.204}

Background Intentional and unintentional injuries are a significant and preventable health concern in Canada with 4.27 million Canadians ages 12 or older suffering an activity limiting injury. Knowledge translation and education among researchers, practitioners and policy makers as well as the continual development of trainees in the area of injury prevention, is paramount for the future health of Canadians.

Methods The Canadian Injury Prevention Curriculum (CIPC) was designed to provide practitioners the understanding of the theory and practice of injury prevention along with the tools needed to develop and implement effective injury prevention programs. The CIPC is targeted toward adult learners (researchers, practitioners and/or policy makers) who develop, implement and/or evaluate programs aimed at reducing the frequency and severity of both intentional and unintentional injury. The last update of this curriculum was in 2010. This project aimed to update the CIPC, using an integrated knowledge translation approach to reflect an evidence-informed approach to injury prevention.

Results The revision occurred over a series of phases: PHASE 1 Update to the current curriculum to reflect an evidence-informed approach to injury prevention (what is injury prevention and defining the problem, risk and protective factors and key determinants of injury, designing/selecting an intervention, implementation and evaluation) in consultation with an adult learning expert; PHASE 2 - Modules were developed for practitioners to further knowledge and application of core knowledge; PHASE 3 - The updated curriculum was made available across Canada to researchers, practitioners and policy makers interested in preventing injury in Canada.

Conclusions The CIPC was updated using an integrated knowledge translation approach. The result was an education tool using an evidence-informed approach to the prevention of injury, 
applicable for researchers, practitioners, policy makers, and junior trainees.

\section{THE UL SAFETY INDEX: QUANTIFYING SAFETY AROUND THE WORLD}

David Wroth, Ahreum Han. Underwriters Laboratories (UL), USA

10.1136/injuryprev-2016-042156.205

Background Assessing the state of safety amongst countries is complex, leading to poor prioritisation of resources amongst safety professionals and policy makers. The UL Safety Index is a quantification of relative safety based on societal influences and unintentional death and injury.

Methods The relationship between the indicators (societal influences and safety frameworks) and outcomes was modelled. Indicators were transformed into an index ranging from 0 (worst) to 1 (best):

$$
\text { Indicator Index Score }=\frac{x_{i}-\min x_{i}}{\max x_{i}-\min x_{i}} \text {, where } x \text { are the explanatory indicators }
$$

Drivers were computed as the arithmetic mean of the Indicators:

$$
\text { Driver Index Score }=\frac{1}{n} * \sum_{i=1}^{n} x_{i}, \text { where } x \text { are the Indicator Indices }
$$

The UL Safety Index is the geometric mean of the three Driver Indices:

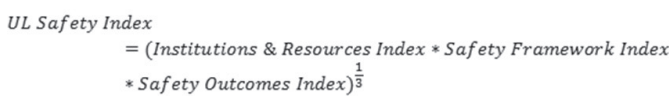

Statistical analysis of indicators and drivers against injury data confirmed correlation with outcomes.

Results Western industrialised nations are at the top of the Safety Index. Sub-Saharan Africa has much to gain from investment in safety drivers. As the Index includes factors of wealth, education and governance, human development and infrastructure issues influence the results. Consequently, solutions that address basic needs will also improve safety. South Central Asia also lags in the Index. Many of the same influences for Africa apply here as well and their Index is also affected by limited participation in international standards development.

Conclusions The relationship between societal drivers and safety outcomes confirm the need for multi-layered improvement strategies. Investment in governance, education, technology, infrastructure and economic development are correlated with fewer unintentional deaths and injuries. This implies that safety outcomes are improved through investment in key development areas. Safety science will continue to be part of a comprehensive approach as hazard mitigation and behaviour change also improve safety outcomes. The UL Safety Index improves visibility into needed investments, leading to initiatives that will save lives globally.

\section{Environmental Safety, Client Safety}

Parallel Mon 3.6

\section{COST-BENEFIT ANALYSIS OF FALL INJURIES PREVENTED BY A PROGRAMME OF HOME MODIFICATIONS}

${ }^{1}$ Michael D Keall, ${ }^{1}$ Nevil Pierse, 'Philippa Howden-Chapman, ${ }^{2}$ Jagadish Guria, ${ }^{3}$ Chris Cunningham, ${ }^{1}$ Michael G Baker. ${ }^{1}$ Otago University, Wellington, New Zealand; ${ }^{2}$ Economic Consultant, Newlands, Wellington, New Zealand; ${ }^{3}$ Massey University, Wellington, New Zealand

\subsection{6/injuryprev-2016-042156.206}

Background Injuries due to falls in the home amongst the general population impose a huge social and economic cost on society. We previously found important safety benefits of home modifications such as handrails for steps and stairs, grab rails for bathrooms, outside lighting, edging for outside steps and slip-resistant surfacing for outside surfaces such as decks.

Methods Following a single-blinded cluster randomised controlled trial (the HIPI trial), we analysed insurance payments for medically-treated home fall injuries. The benefits in terms of the value of DALYs averted and social costs of injuries were extrapolated to a national level and compared with the costs of the intervention.

Results Costs per injury per time exposed to the modified homes compared to the unmodified homes showed a reduction in the insurer costs of home fall injuries of 36\% (95\% CI: 5\%-59\%). The social benefits of injuries prevented were estimated to be at least 9 times the costs of the intervention. The benefit cost ratio can be at least doubled for older people and those with a prior history of fall injuries.

Conclusions This is the first randomised controlled trial to our knowledge to examine the benefits of home modification for reducing fall injury costs in the general population. The results show a convincing economic justification for undertaking relatively low-cost home repairs and installation of safety features.

\section{PARTNERING TO FOCUS ON CHILD INJURY PREVENTION - THE SAFEKIDS NEW ZEALAND AND HOUSING NEW ZEALAND DRIVEWAY RUN OVER CAMPAIGN}

${ }^{1}$ Alessandra Francoia, ${ }^{2}$ Ann Weaver. ${ }^{1}$ Safekids New Zealand; ${ }^{2}$ Housing New Zealand, New Zealand

10.1136/injuryprev-2016-042156.207

Background This presentation demonstrates the success of a Driveway Run over Campaign by using intersectoral collaboration to support the implementation of this child injury prevention initiative. Incorporating increased awareness, behaviour change, environmental change, and advocacy.

Housing New Zealand Corporation (HNZC) is New Zealand's largest landlord, and houses over 200,000 people. HNZC customers are lower income households, and indigenous peoples are over-represented. Most HNZ households include children. Safekids and HNZC have a shared interest in increasing the safety of vulnerable children and their families. Since 2006, Safekids and HNZC have collaborated to reduce the risk of driveway run over injuries in HNZC properties.

This presentation will describe the key components of the partnership, including the national context for this work, shared 